\title{
Cooperação Transfronteiriça e Desenvolvimento Local no âmbito do Mercosul: uma Experiência de Consórcio Intermunicipal
}

\section{Cross-Border Cooperation and Local Development within Mercosur: an Experience of Intermunicipal Consortium}

Hoyêdo Nunes Lins*

\begin{abstract}
Resumo: Embora sinuoso e crivado de desigualdades, o Mercosul favoreceu iniciativas de cooperação transfronteiriça aptas a ajudar comunidades a enfrentar problemas e aproveitar oportunidades coletivamente. Este artigo focaliza uma experiência específica de cooperação transfronteiriça no Cone Sul, dirigindo o olhar para o Consórcio Intermunicipal da Fronteira (CIF), envolvendo os municípios brasileiros de Dionísio Cerqueira, em Santa Catarina, Barracão e Bom Jesus do Sul, no Paraná, e o município argentino de Bernardo de Irigoyen, situado na província de Misiones. O estudo começa pelas desigualdades no Mercosul e, depois, aborda a cooperação no marco da integração, as interações internacionais dos entes subnacionais e as oportunidades de cooperação ligadas à integração regional. Na sua maior seção, dedica-se à experiência do CIF.
\end{abstract}

Palavras-chave: Mercosul. Cooperação local. Consórcio Intermunicipal da Fronteira.

Abstract: The Mercosur path looks sinuous and riddled with inequalities, but has favored cross-border cooperation that may help communities to face problems and explore opportunities collectively. The article addresses this subject looking at a specific experience of cross-border cooperation in the Southern Cone, the one concerned with the Consórcio Intermunicipal da Fronteira (CIF), formed by Dionísio Cerqueira (Santa Catarina), Barracão and Bom Jesus do Sul (Paraná), and also by Bernardo de Irigoyen (Misiones, Argentina). The text firstly discusses the issue of inequalities within Mercosur, and then deals with cooperation in integration processes, international interactions involving subnational actors and cooperation opportunities observed in the Southern Cone. In its largest section, the article concentrates on the CIF.

Keywords: Mercosur. Local cooperation. Consórcio Intermunicipal da Fronteira.

JEL Classification: F55; H70.

\section{Introdução}

Indicativos de processos marcantes nas relações econômicas e políticas internacionais, os termos integração e cooperação não são sinônimos. $O$ primeiro refere-se a situações criadas por acordos ou tratados e o segundo, a realidades que

Doutor em Geografia e Organização do Espaço pela Université de Tours, França Professor titular do Departamento de Economia e Relações Internacionais da Universidade Federal de Santa Catarina (UFSC). E-mail: hoyedo.lins@ufsc.br 
prescindem de tais arcabouços, podendo resultar de convergências espontâneas de interesses. Porém, ambos tendem à articulação e ao paralelismo, pois a integração costuma favorecer a cooperação, e esta pode contribuir para a emergência ou o fortalecimento daquela.

O processo de integração relativo ao Mercosul, por exemplo, foi precedido e acompanhado por ações cooperativas entre os países membros. Uma ilustração refere-se à cooperação em termos nucleares entre Argentina e Brasil, cujas ações foram registradas antes da escalada que resultou no Mercosul e se revelaram importantes na própria redução das arestas ligadas à rivalidade histórica entre os dois países. Entretanto, o Mercosul impulsionou essa cooperação, que ganhou a companhia de outras iniciativas com sentido semelhante.

Este artigo ocupa-se de cooperação no seio do Mercosul. Seu foco é, todavia, restrito: diz respeito, sobretudo, ao tema da cooperação transfronteiriça, envolvendo esferas subnacionais de ação política, econômica e social. Nessa direção, e estribado em pesquisa bibliográfica e documental, o estudo tem como principal objeto o Consórcio Intermunicipal da Fronteira (CIF), uma iniciativa que abrange, no lado brasileiro, Dionísio Cerqueira (extremo oeste de Santa Catarina), Barracão e Bom Jesus do Sul (sudoeste do Paraná) e, no lado argentino, Bernardo de Irigoyen (província de Misiones). O fato de tal experiência implicar entes subnacionais de diferentes países e estados brasileiros, em recorte político-territorial incrustado no centro de gravidade do Mercosul, aguçou o interesse por esse assunto específico e pode ser apontado como uma justificativa da sua escolha para esta pesquisa.

O objetivo principal é duplo. De um lado, busca-se assinalar que a cooperação internacional envolvendo entes subnacionais há de ser vista como prática com sentido estratégico em processos de integração, pelo que pode representar para a promoção do desenvolvimento no plano local ou regional, algo tanto mais importante tendo em vista que as desigualdades socioespaciais em escala de bloco de países geralmente impõem grandes desafios às dinâmicas integracionistas. De outro lado, pretende-se salientar que, em meio a uma lenta, mas progressiva ampliação das ações de cooperação internacional envolvendo entes subnacionais no Brasil, chamou a atenção o processo referente ao indicado CIF, almejando-se, aqui, caracterizar o território implicado, apresentar o conjunto de ações previstas e comentar e discutir algumas de suas realizações. A indagação básica, norteadora da pesquisa sobre tal consórcio, relaciona-se aos contornos do segundo objetivo: $\mathrm{O}$ que se pode dizer sobre o contexto, o conteúdo/abrangência e algumas das principais concretizações dessa iniciativa transfronteiriça?

Este artigo possui mais quatro seções, além desta introdução, todas desdobradas em vários tópicos: a segunda seção focaliza o problema das desigualdades de desenvolvimento nos processos de integração, em termos gerais; a terceira dis- 
corre sobre o tema das ações internacionais dos entes políticos e administrativos subnacionais, com ilustrações sobre o Mercosul; a quarta explora a experiência de cooperação transfronteiriça referente ao CIF; a quinta traça as considerações finais.

\section{Integração, Desigualdades e Reações Institucionais}

A experiência internacional indica que desigualdades socioespaciais de desenvolvimento geralmente rimam com tensões políticas geradoras de riscos e ameaças à coesão social. Esse aspecto confere grande importância a tais desigualdades, seja em termos analíticos, seja, principalmente, no campo da ação política para promover o desenvolvimento. Esse problema é especialmente relevante nos processos de integração.

\subsection{Desigualdades na Integração}

Nos processos de integração regional, é preciso considerar o peso das desigualdades de desenvolvimento. Como assinala Jaguaribe (2000, p. 41), as "[...] integrações só funcionam se forem boas para todo mundo, não necessariamente igualmente boas para todo mundo, mas é necessário que seja para todos.". Não surpreende, assim, que a questão dessas desigualdades tenha chamado a atenção rapidamente na experiência de integração tida como paradigmática, relativa à Europa (BYÉ, 1958). O interesse por esse problema se mantém, seja com respeito ao caso europeu, seja por outros processos do gênero, conforme sugerem Krugman (1991) e Venables (2003).

O Mercosul registra profundas assimetrias socioespaciais entre países e entre regiões subnacionais (SOUZA; OLIVEIRA; GONÇALVES, 2010). Isso é fato mesmo no centro-sul brasileiro e nas áreas de Argentina, Paraguai e Uruguai que formam o grande core desse processo de integração, onde há importantes disparidades de desenvolvimento na escala local ou territorial. O problema ensejou tentativas de análise de vários pesquisadores, entre eles Blyde, Fernández-Árias e Giordano (2008).

Inquietações sobre esse assunto apareceram já nos primeiros passos do Mercosul. Poucos anos após a assinatura do Tratado de Assunção, Laurelli e Montaña (1994, p. 142, tradução nossa) escrevem: "O Mercosul avança com uma dinâmica própria alheia aos atores cotidianos, e, assim, o processo de integração está se estruturando por fora do debate dos distintos âmbitos das sociedades nacionais". As autoras alertavam para o risco de exclusão de vários espaços locais, "[...] seja por motivos geográficos ou em razão do perfil de suas economias; nesse caso, uma integração sem salvaguardas provocaria um efeito de polarização, acentuando as 
disparidades regionais já existentes [...]" (LAURELLI; MONTAÑA, 1994, p. 147, tradução nossa). Como resultado, aprofundar-se-ia a "[...] iniquidade do atual modelo de distribuição, incrementando a fragmentação e a heterogeneidade social" (LAURELLI; MONTAÑA, 1994, p. 147, tradução nossa).

A criação do Fundo para a Convergência Estrutural do Mercosul (Focem), em 2004, sinalizou o reconhecimento de que tais problemas são prioritários. O objetivo desse fundo é financiar "[...] programas para promover a convergência estrutural; desenvolver a competitividade; promover a coesão social, em particular das economias menores e regiões menos desenvolvidas, e apoiar o funcionamento da estrutura institucional e o fortalecimento do processo de integração" (art. $1^{\circ}$ do $\mathrm{CMC} \mathrm{n}^{\circ}$ 18/05, cf. MERCOSUL/CMC/DEC, 2005).

São áreas-chave, para destinação dos recursos, a infraestrutura física e a estrutura produtiva, mas contemplam-se avanços também no tocante aos índices sociais dos Estados partes e ao fortalecimento institucional do bloco. Aberto a quaisquer entidades públicas dos respectivos países, o Focem exibe programas de convergência estrutural e de desenvolvimento da competitividade, além dos dirigidos à coesão social, mirando áreas como saúde, educação e capacitação profissional, assim como o combate à pobreza. Na composição dos recursos, Brasil, Argentina, Uruguai e Paraguai participam com 70\%, 27\%, 2\% e 1\%, respectivamente, que se invertem na distribuição: cabem 10\% para Brasil e Argentina, individualmente, $32 \%$ ao Uruguai e $48 \%$ ao Paraguai.

Vários projetos têm sido executados nesse âmbito institucional. A página eletrônica oficial do Mercosul ${ }^{1}$ informa sobre os aprovados desde o início e a página do próprio fundo ${ }^{2}$ refere às áreas de aplicação dos recursos. Ao lado de outros instrumentos, como o Fundo Mercosul de Garantias para Micro, Pequenas e Médias Empresas, criado em 2008, o Fundo de Agricultura Familiar do Mercosul, também de 2008, e o Instituto Social do Mercosul (ISM), fruto da Decisão do $\mathrm{CMC} \mathrm{n}^{\circ}$ 03/07 (cf. MERCOSUL/CMC/DEC, 2007), o Focem constitui iniciativa de alcance macrorregional, por assim dizer, "comunitária". Sua criação representa, ao mesmo tempo, resposta à existência de desigualdades socioespaciais e medida compensatória ao tipo de problema que Laurelli e Montaña (1994) detectam no início do Mercosul. Assim, a motivação subjacente nada teve de fortuita, pois uma integração desacompanhada de cautelas representa ameaça de aumento da polarização e, por conseguinte, das disparidades socioterritoriais.

$\overline{1}$ Disponível em: $<$ www.mercosur.int $>$.

2 Disponível em: <www.mercosur.int/focem >. 


\subsection{Integração e Cooperação}

Para além da criação de instrumentos com aplicação territorialmente abrangente, como o Focem, processos de integração favorecem e, mesmo, promovem iniciativas de cooperação em escala local, conforme assinalado na introdução. Essa possibilidade tende a interpelar a capacidade dos agentes locais quanto à concepção e urdidura de vínculos e interações para, no marco da aproximação de interesses e da ação coletiva, enfrentar problemas e melhorar a participação na própria dinâmica integracionista.

Cooperar é uma prática que ganhou contornos de palavra de ordem nas liturgias de planejamento e de promoção do desenvolvimento em diferentes planos territoriais: "As novas formas de governança mirando a competitividade local e regional, como a maioria das próprias estratégias de desenvolvimento, são cada vez mais orientadas para a cooperação [...]" (ORGANISATION FOR ECONOMIC COOPERATION AND DEVELOPMENT, 2005, p. 12, tradução nossa). As ações desse tipo apresentam-se, assim, em sintonia com a crescente importância da dimensão local para a reflexão sobre o desenvolvimento e a sua promoção (VÁZQUEZ BARQUERO, 2002).

Assinala-se que um dos fatores da proeminência adquirida por essa escala, para o planejamento e a promoção do desenvolvimento, tem a ver com a descentralização de várias funções do Estado, um movimento observado em diversas experiências nacionais (BOISIER, 2004). Esse processo adquiriu feições de movimento amplo, inclusive - talvez principalmente - nas zonas centrais do capitalismo, desde os anos 1980 (GAUDEMAR, 1989; MOULAERT; SWYNGEDOUW; WILSON, 1988).

O Cone Sul latino-americano não foi exceção nesse movimento. Na Argentina, por exemplo, a transferência de funções públicas para níveis políticos e administrativos subnacionais ganhou vigor desde a década de 1990 (MADOERY, 2011). No Brasil, a Constituição Federal de 1988 representou "impulso legislativo" à descentralização (BRASIL, 1988), ampliando o escopo de ação dos estados e, sobretudo, dos municípios (SOUZA, 2001).

Ressaltar o caráter geral dessa descentralização não significa postular que outras escalas de ação perderam importância. É essencial, no encorajamento e apoio ao desenvolvimento, a articulação de medidas protagonizadas em diferentes níveis territoriais e institucionais, do local ao nacional, e, mesmo, no plano internacional (ECONOMÍA..., 2009). De toda maneira, é fato que as instâncias regionais e locais (ou estaduais e municipais) foram cada vez mais implicadas, abrindo novos espaços institucionais para o planejamento e a promoção do desenvolvimento.

Nos processos de integração, importantes ações cooperativas nessas escalas, merecedoras de realce particular, dizem respeito às faixas de fronteira. Porém, esse 
tipo de cooperação tende a se mostrar bem-sucedido quando também mobiliza diferentes patamares de governo (com ligações verticais), para além das órbitas locais, quer dizer, transcendendo aquelas que envolvem somente regiões, estados, províncias, departamentos ou municípios (em vínculos mais horizontais).

No Mercosul, como em outros processos do gênero, a integração facilita a cooperação transfronteiriça para criar espaços de intercâmbio, aproveitar as complementaridades, somar os esforços e desenvolver diversas modalidades de projetos conjuntos. A participação dos vários atores sociais locais mostra-se importante, com práticas que lhes permitam opinar e contribuir para a solução dos problemas vivenciados. A questão em foco é o entrelaçamento das esferas subnacional e internacional no estímulo ao desenvolvimento, assunto que, de um modo geral, aparece nos debates recentes sobre as relações internacionais, inclusive no Brasil.

\section{Ações Internacionais de Entes Subnacionais}

Nesta seção, fala-se, primeiramente, do aumento de participação dos entes subnacionais nas práticas cooperativas de alcance internacional, de uma maneira ampla. Depois, dirige-se o olhar ao Mercosul.

\subsection{Cooperação Internacional com Protagonistas Subnacionais}

O contexto mais abrangente da problemática em foco refere-se à situação do Estado nacional na globalização contemporânea. Para autores como Jacobson (1997) e Robinson (1998), o Estado central resultou enfraquecido devido à maior presença das empresas multinacionais nas atividades econômicas e ao crescente peso de processos políticos ocorrendo acima e abaixo da escala nacional, entre outros fatores. No entanto, a controvérsia é a regra, pois argumentos no sentido contrário também se mostram robustos, como observam Mann (1997) e Rapoport (1997).

Interessa aqui, todavia, o aspecto da crescente desenvoltura da atuação política e institucional dos entes subnacionais na promoção do desenvolvimento. $\mathrm{O}$ Estado nacional permanece implicado, em maior ou menor grau, mas ampliou-se a participação relacionada às outras dimensões, evidenciando-se voluntarismo e capacidade de ação em nível regional e local, na contramão das percepções sobre a quase exclusividade dos determinantes mais gerais. A cidade, mormente quando de grande porte, sobressai nesse processo: para Sassen (2010, p. 91), "A perda do poder no nível nacional leva à possibilidade para novas formas de poder e política [...] [abrirem] possibilidades para uma geografia da política que relaciona espaços subnacionais através das fronteiras. As cidades, em primeiro lugar, estão nessa nova geografia.". 
A cooperação internacional, na perspectiva aqui abordada, representa o aspecto central dessas iniciativas dos governos locais, as quais autorizam postulações, como a de Alger (1999, p. 195, tradução nossa), sobre observar-se, hoje, um "[...] crescente papel desempenhado pelas autoridades locais nos assuntos mundiais [...]”. Essas ações geralmente contemplam a promoção do desenvolvimento, sugerindo que esse tipo de cooperação constitui resposta aos desafios da globalização. Sua incidência manifesta-se notadamente nas redes internacionais de cidades, formadas por governos locais, e ostentando vários objetivos e modos de interação (SALOMÓN, 2009).

Nota-se que a importância das autoridades locais em processos desse tipo é amplamente reconhecida, como postula o Banco Mundial no documento Cities in transition: World Bank urban and local government strategy (THE WORLD BANK, 2000). De fato, a Organização das Nações Unidas (ONU), na sua Commision for human settlements, enxerga nessas autoridades a condição de parceiros essenciais para executar a Habitat Agenda, mesmo assinalando a necessidade de mais rapidez no fortalecimento da cooperação entre governos centrais e locais (UNITED NATIONS ADVISORY COMMITTEE OF LOCAL AUTHORITIES, 1999). O realce atribuído pelo Banco Mundial à escala internacional das medidas transparece em posições como esta: "Coalizões nacionais e internacionais precisam ser fortalecidas para amparar o aumento dos serviços urbanos em nível de comunidade [...]" (THE WORLD BANK, 2000, p. 9, tradução nossa).

No Brasil, iniciativas dessa natureza têm ocorrido no âmbito da paradiplomacia, isto é, das interações internacionais de estados e municípios. Segundo Saraiva (2004) e Vigevani (2006), essa prática cresceu nas últimas décadas no país, embora discreta e tardiamente até sua incorporação nas respectivas esferas institucionais. A criação, em 1997, no Ministério das Relações Exteriores, da Assessoria de Relações Federativas, tornada, em 2003, Assessoria Especial de Assuntos Federativos e Parlamentares, é um marco na institucionalização das interações entre o Governo Federal e as autoridades estaduais e municipais no tocante às ações exteriores das unidades subnacionais (PEREIRA, 2005).

Desde então, aumentou o envolvimento internacional de poderes subnacionais brasileiros, principalmente em redes implicando esferas similares em outros países. Sistematizações de experiências, como as apresentadas por Marcovitch e Dallari (2014), sobre vários estados e municípios brasileiros são sugestivas a respeito dessa evolução, que se traduz igualmente na presença de representações do Ministério das Relações Exteriores em diversos estados e na abertura, por alguns destes, de escritórios em outros países, para não falar do estabelecimento de diversos tipos de acordos (VIGEVANI, 2006).

De todo modo, Salomón (2008, p. 147, tradução nossa) considera ser uma novidade no Brasil a "[...] consciência, por parte dos principais atores envolvidos, 
de que essas atividades fazem parte de um setor que convém repensar e ativar.". O engajamento do Itamaraty é ilustrativo do tipo de percepção que parece ter adquirido corpo: representante desse ministério em um seminário realizado em São Paulo (em março de 2002), no âmbito do projeto "Gestão pública estratégica de governos subnacionais frente aos processos de inserção internacional e integração latino-americana", uma parceria entre o Centro de Estudos de Cultura Contemporânea e a Pontifícia Universidade Católica de São Paulo (SEMINÁRIO INTERNACIONAL..., 2002), assinalou há 15 anos, que repercutiu naquela instituição o fato de que "Cada vez mais esses governos subnacionais participam na organização e na condução da política externa brasileira." (DANIEL, 2002, p. 45).

A pedra angular nessas interações internacionais costuma ser a cooperação com vistas à promoção do desenvolvimento. O pragmatismo, recobrindo tentativas de equacionamento de problemas concretos na escala eminentemente local, caracteriza essas iniciativas, como salienta Vigevani (2006, p. 130): “[...] há ativismo em questões como convênios tecnológicos, cooperação técnica, empréstimos, turismo, investimentos, entre outras, mas nunca houve um movimento em torno de qualquer outro tema que não estivesse ligado a questões locais." Em geral, conforme captado através de survey realizada por Milani e Ribeiro (2011) em 72 municípios, no biênio 2007-2008, essas relações - sobretudo quando implicam cidades - miram trocas de boas experiências em políticas urbanas. $\mathrm{O}$ foco principal, assim, é o que esses autores designam como gestão local internacional, envolvendo o "[...] desenvolvimento de novas estratégias organizacionais de municípios e parcerias locais/globais de governança, particularmente em termos de programas de infraestrutura, assistência técnica e cooperação para o desenvolvimento." (MILANI; RIBEIRO, 2011, p. 34, tradução nossa).

O Mercosul, cujos movimentos nesse campo ensejaram a criação da referida Assessoria de Relações Federativas no Itamaraty, favoreceu o surgimento ou ampliação de espaços institucionais e de oportunidades para interações com esse perfil.

\subsection{Sentido e llustração da Cooperação Local no Mercosul}

Por muito tempo, desde a assinatura do Tratado de Assunção, a cooperação transfronteiriça esteve praticamente ausente das principais providências institucionais do Mercosul. É verdade que, já em 1995, deu-se a criação da rede Mercociudades, ${ }^{3}$ uma iniciativa de autoridades das maiores cidades do Cone Sul para promover o intercâmbio e a cooperação. Com estrutura própria e vários níveis de responsabilidade e ação, permitindo diferentes tipos de atividades, essa

3 Mais informações em: <www.mercociudades.org/pt-br>. 
rede oferece novos espaços de participação na arquitetura institucional do Mercosul, incluindo reivindicações dos municípios junto aos governos centrais.

Nesse ambiente de tentativas de avanço institucional na cooperação, algumas ações podem ser repertoriadas para ilustrar os vínculos entre agentes locais no Mercosul. Bastaria, contudo, aludir a uma experiência envolvendo Rosario, maior cidade da província argentina de Santa Fe, que emergiu no marco da rede Mercociudades e tomou a forma - a partir de proposta dirigida por agentes locais ao governo municipal - de um acordo com o Serviço Brasileiro de Apoio às Micro e Pequenas Empresas do Paraná (Sebrae/PR). O resultado foi a Acta acuerdo de fundamentos para la elaboración de proyectos conjuntos, de maio de 2009, conforme descrição de Geneyro et al. (2010).

Essa investida envolvia cooperação técnica voltada à melhoria do ambiente empreendedor para empresas de menor porte, com apoio recíproco. Pelo acordo, a Agencia de Desarrollo Región Rosario se beneficiaria das atividades do Centro de Desenvolvimento de Tecnologias para Integração Transfronteiriça de Micro e Pequenas Empresas do Mercosul e América Latina (Sebrae/CDT-AL), ligado a projeto do Sebrae Nacional, operacionalizado pelo Sebrae/PR e instalado no Parque Tecnológico Itaipu, em Foz do Iguaçu. ${ }^{4}$

Todavia, essa experiência, embora transfronteiriça, não se caracteriza como cooperação na faixa da fronteira, ambiente que tardou a registrar uma institucionalidade própria na estrutura do Mercosul. De fato, envolvendo especificamente as áreas de fronteira, só em 2002 apareceu algo como o Grupo Ad Hoc sobre Integração Fronteiriça, destinado a promover interações entre as comunidades fronteiriças dos países do bloco (SAUSI; ODDONE, 2010). Em 2004, surgiu o Fórum Consultivo de Municípios, Estados Federados, Províncias e Departamentos do Mercosul para estimular o diálogo e a cooperação dos governos nessas esferas, objetivando atingir soluções coordenadas para problemas e a promoção do bem-estar e da qualidade de vida nas respectivas jurisdições. Em 2007, foi criado o grupo de trabalho de integração fronteiriça.

A faixa fronteiriça é tanto mais merecedora de atenção tendo em vista que, entre outros aspectos, é elevado o número de cidades gêmeas que a pontilham. Essa característica confere sentido à expressão "socioeconomia da fronteira", em referência a diversos de seus pontos ou ambientes. O traço mais forte é o constante fluxo de pessoas, mercadorias e serviços que atravessam as "membranas" representadas pelas estruturas de controle fronteiriço.

Assinala-se que a geografia das relações mediadas por esse aparato de controle é variável, o que faz pensar sobre os vínculos entre áreas urbanas transfronteiriças e seus espaços regionais. Indagações sobre a ocorrência de enclaves ou sobre as interações entre tecidos urbanos transfronteiriços e seus entornos regionais

4 Mais informações em: <www.sebraecdt-al.com.br>. 
mostram-se, desde logo, pertinentes. Situações de enclave impõem agenda de promoção do adensamento dos vínculos, visando uma melhor distribuição socioespacial de condições e oportunidades para o desenvolvimento. Tem importância, nessa perspectiva, o apoio às externalidades, principalmente na forma de economias de aglomeração representativas de benefícios para todo o espaço regional transfronteiriço.

Essa questão é relevante com respeito ao Mercosul, cujo quadro justifica iniciativas, nas áreas fronteiriças, voltadas à interpenetração social e econômica entre ambiente urbano e hinterland. De fato:

Muitos estudos discutem que as áreas fronteiriças podem fun-
cionar como espaços de criação de possibilidades de desenvol-
vimento, áreas de transiçãa, contato, articulação, com especial
vivacidade e dinamismo próprio. As cidades contíguas que se
estendem entre países e exercem, muitas vezes, atividades eco-
nômicas similares e funções urbanas complementares poderiam
dar origem a estruturas bi/trinacionais com articulação produtiva
e transformação territorial [...]. Entretanto, contrapondo-se ao es-
paço único de ocupação, prevalecem ainda [na região] tensões
históricas fronteiriças e, mais que tudo, assimetria entre as partes,
levando a quadros de expressiva desigualdade, que potenciali-
zam os mais diversos tipos de conflitos. [...] [Mostra-se necessário,
portanto,] [...] desconstruir a noção de um mosaico de pedaços
de países independentes que se avizinham, e formular e efetivar
políticas integradoras. (MORAIS; COSTA, 2010, p. 700).

Nesse contexto, ganha realce, por exemplo, uma iniciativa como o Plano de Integração Fronteiriço "Cidade Gaúcha”, capaz de frutificar na sua área de incidência imediata e até indireta. A execução implica trecho de fronteira entre Argentina e Brasil, no extremo sul do segundo envolvido, segundo Geneyro et al. (2010), por iniciativa conjunta de lideranças e agências de desenvolvimento das cidades gêmeas de Paso de los Libres, na província argentina de Corrientes, e Uruguaiana, no estado do Rio Grande do Sul, no Brasil. O objetivo maior era estimular o desenvolvimento transfronteiriço por meio de instrumentos como a conscientização dos habitantes sobre a importância da integração social e a difusão do sentimento de que, enquanto atores numa socioeconomia fronteiriça, participam de um mesmo projeto de inserção na dinâmica internacional.

\section{Uma Experiência em Curso de Cooperação Transfronteiriça no Mercosul}

Aborda-se nesta seção o CIF assinalado na introdução do artigo. Contudo, para colocar a iniciativa desse consórcio em perspectiva, alude-se antes ao modo como a problemática da integração foi encarada na região sul do Brasil nos primeiros anos do Mercosul. 


\subsection{Alguns Temas em presença no Brasil Meridional no início do Mercosul}

Na região sul do Brasil, o Mercosul ganhou contornos de assunto importante logo depois da assinatura do Tratado de Assunção, em 1991, haja vista a localização geográfica e o perfil econômico dos respectivos estados. Imaginava-se, nessa escala, que a participação transcenderia - como de fato ocorreu - as trocas comerciais e os investimentos, alcançando, de algum modo, o que se poderia chamar de integração social e/ou cultural, vinculada inclusive à maior mobilidade ou circulação de cidadãos do Cone Sul.

Em Santa Catarina, por exemplo, a própria estrutura produtiva do estado fazia imaginar reflexos fortes. Têm realce nessa estrutura um tecido industrial robusto, diversificado e presente em várias regiões e também um setor primário que, sobretudo no grande oeste catarinense, interage fortemente com a indústria. $\mathrm{Na}$ base das expectativas - que no geral justificavam-se para toda a região sul - figuravam os esperados efeitos da intensificação do comércio interno ao Cone Sul e os investimentos assim estimulados. Esses fluxos haveriam de provocar reestruturação produtiva em diferentes atividades, com repercussões socioespaciais.

Questões dessa ordem perpassaram os debates, acadêmicos ou não, realizados no sul do país sobre a integração. Nessas oportunidades, quase sempre se indagou sobre as possíveis consequências sociais da intensificação da concorrência no mercado interno, por conta da liberalização comercial. Pressões por ajustes mais ou menos abrangentes eram tidas como inevitáveis, com consequências no plano do emprego. Os setores agrícola e agroindustrial sobressaíam nessas discussões, principalmente devido às condições competitivas da Argentina (LINS, 1994).

Muito menos atenção foi dedicada à cooperação no início do Mercosul. Todavia, o assunto não deixou de interessar ao setor privado, pois empresas de pequeno e médio portes do sul do Brasil realizaram acordos de cooperação com empresas congêneres argentinas. Atuando em vários setores, mas na maioria em produção metalomecânica e de artigos de vestuário, essas empresas efetuaram acordos de, notadamente, representação comercial (simples na maioria e cruzada em alguns casos) e complementação produtiva, sobretudo para aumentar e diversificar seus mercados (pelo acesso às redes de comercialização dos parceiros) e para realizar economias de escala (LINS; BERCOVICH, 1995).

Iniciativas desse tipo certamente tiveram importância para as empresas. Porém, não se pode afirmar que foram duradouras ou inocularam prática cooperativa capaz de efetivamente contribuir para a promoção do desenvolvimento no seu entorno. Tratava-se, muito mais, de ações episódicas, em geral ligadas a circunstâncias e associadas às individualidades empresariais, ainda que esforços institucionais (por exemplo, envolvendo o Sebrae) tenham surgido para lubrificar e dar espessura aos procedimentos. Não por acaso, diagnósticos recentes, elabora- 
dos no âmbito da rede Mercociudades, postulam que lograr sucesso na integração produtiva entre localidades do Cone Sul permanece sendo um objetivo desafiador na dinâmica da integração (GENEYRO et al., 2010).

Também no tipo de cooperação privilegiado neste artigo - implicando particularmente o setor público no plano subnacional fronteiriço -, os anos 1990 testemunharam algumas ações no sul do Brasil. Uma delas, com acenos de enfrentamento conjunto de problemas comuns, envolveu os estados que formavam o Conselho de Desenvolvimento da Região Sul (Codesul) e as províncias argentinas integrantes da Comisión Regional de Comercio Exterior del Nordeste Argentino y Litoral (Crecenea-Litoral). Um resultado foi o Projeto Crecenea-Codesul, com estudos e propostas sobre questões pontuais, principalmente de infraestrutura, sem restringir-se à faixa fronteiriça e sem deixar registro de desdobramentos importantes. Subjacentes às medidas, teria figurado a conjugação de interesses dos governantes (estaduais, provinciais) de turno, pouco fértil para uma agenda de efetiva cooperação institucional voltada ao desenvolvimento em importante território do epicentro da integração.

\subsection{Consórcio Intermunicipal da Fronteira}

Nas condições descritas, chama a atenção que, quase duas décadas após a assinatura do Tratado de Assunção, tenha-se assistido no sul do Brasil a uma iniciativa como o CIF. Sua criação ocorreu em abril de 2009, pelos municípios brasileiros de Dionísio Cerqueira, no extremo oeste do estado catarinense, e Barracão e Bom Jesus do Sul, no sudoeste do Paraná, com base em autorização outorgada por leis municipais daquele ano, e também pelo município argentino de Bernardo de Irigoyen, em General Manuel Belgrano, um departamento da Provincia de Misiones, no nordeste da Argentina. A Figura 1 situa os integrantes do CIF em termos macrorregionais. 
Figura 1 - Localização de Barracão, Bernardo de Irigoyen, Bom Jesus do Sul e Dionísio Cerqueira, membros do CIF

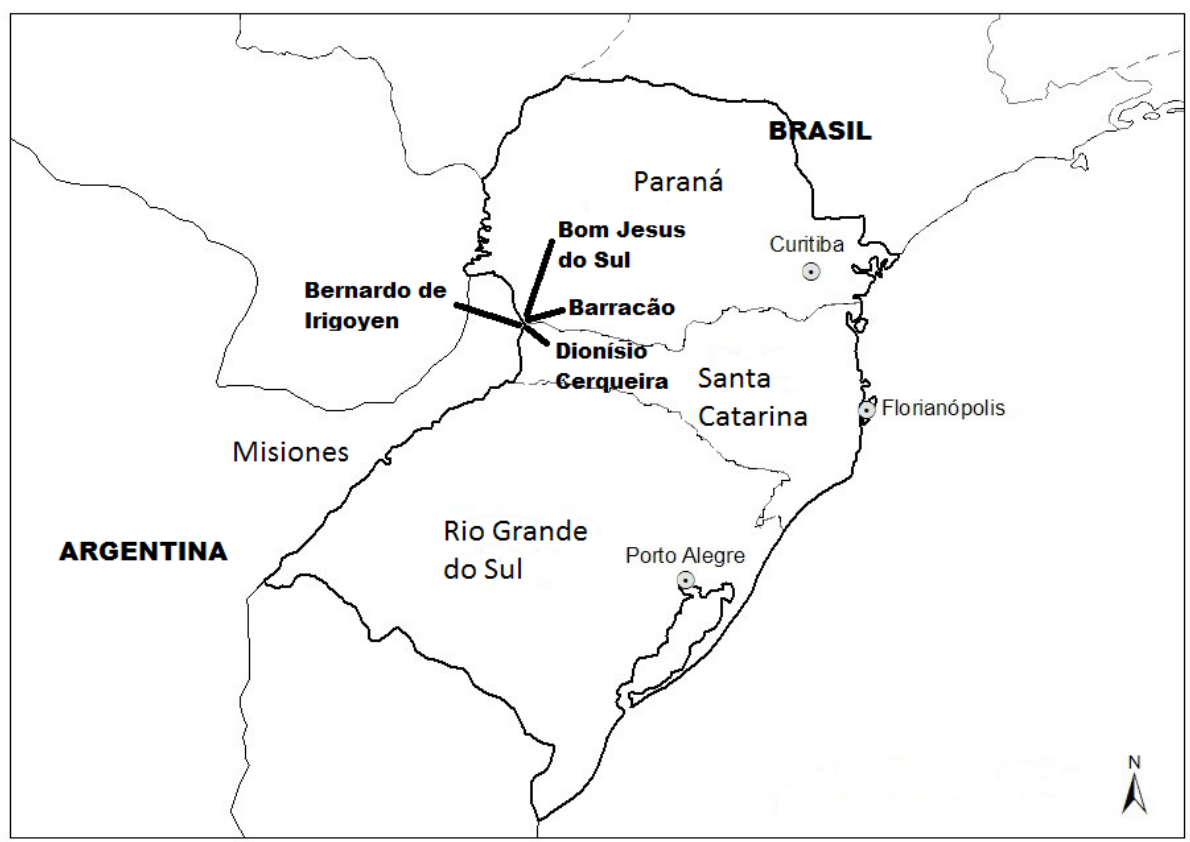

Fonte: Elaboração própria.

A iniciativa, cujo perfil desperta interesse em outros ambientes fronteiriços do Mercosul, começou em meados de 2008 e adquiriu contornos finais em menos de um ano. Segundo Debona (2011), os respectivos prefeitos convergiram para o entendimento de que, em termos práticos, seus municípios formam um único tecido urbano, razão pela qual os problemas de cada um - iguais ou muito semelhantes - seriam melhor enfrentados mediante conjugação de forças, de modo cooperativo. Essa percepção marca o Protocolo de Intenções de março de 2011, celebrado em meio a relações verticais entre o território implicado e esferas institucionais mais amplas: foram signatários os prefeitos municipais (incluindo o intendente ${ }^{5}$ de Bernardo de Irigoyen), os governadores de Santa Catarina, Paraná e Misiones, o Ministro do Turismo desta província e o responsável pela Secretaria de Desenvolvimento Regional de Dionísio Cerqueira (CONSÓRCIO INTERMUNICIPAL DA FRONTEIRA, 2013a).

O sentido de união de esforços permeia notadamente o Protocolo de Intenções firmado em junho de 2013 pelos três municípios brasileiros, com respaldo

5 Prefeito. 
em leis municipais aprovadas naquele ano e em legislação federal. Esse protocolo constitui o CIF como associação pública com personalidade jurídica de direito público e natureza autárquica, detalhando seus aspectos de funcionamento e determinando a localização da sede em Barracão, assim como a escolha da diretoria por votação pela assembleia geral para mandatos de um ano. A inclusão de Bernardo de Irigoyen no previsto Gabinete de Gestão Integrada Intermunicipal é considerada no artigo $23^{\circ}$ desse protocolo (CONSÓRCIO INTERMUNICIPAL DA FRONTEIRA, 2013b).

Merece destaque a rapidez observada entre a demonstração de interesse pela criação de tal consórcio e a concretização da iniciativa, sugerindo capacidade local de articulação política e fértil interlocução envolvendo diferentes esferas da administração pública. Há de ter favorecido essa agilidade o próprio escopo transfronteiriço do empreendimento, com o incrustado sentido estratégico, ainda mais pela sua posição no epicentro do Mercosul. No entanto, a experiência pregressa na região implicada também não deveria ser desconsiderada como provável elemento facilitador: como indicado anteriormente, em meados da década de 1990, os estados brasileiros do Codesul e as províncias argentinas do Crecenea alinhavaram os termos do Projeto Crecenea-Codesul, com um leque de propostas representativas de interesses conjuntos de governantes de ambos os lados da fronteira. O sentido do CIF, portanto, no tocante à projeção transfronteiriça, não parece ter sido algo exatamente novo na área, não obstante a grande diferença de escala comparativamente à tentativa anterior.

De toda maneira, é importante salientar que, com respeito ao caráter de cooperação intermunicipal, o consórcio em estudo se insere em um contexto de proliferação desse tipo de prática no Brasil. O movimento ganhou vigor e visibilidade na esteira das mudanças trazidas pela Constituição Federal de 1988, que praticamente impuseram, como assinalado anteriormente, a descentralização administrativa em muitos aspectos, com transferência de atribuições do governo central para governos estaduais e, principalmente, para prefeituras municipais, no que representou o surgimento de novos arranjos em gestão pública no país. Nesse marco, a cooperação intermunicipal, baseada no compartilhamento de interesses, fez surgirem no Brasil vários tipos de ações conjuntas com vistas ao equacionamento de problemas envolvendo, por exemplo, transporte, saneamento, habitação, lixo e energia. Segundo Farah (2003, p. 86), "Os consórcios intermunicipais constituem a forma institucionalizada dessa cooperação que se encontra mais difundida no país, existindo já em diversas regiões e em diferentes setores [...]”, notadamente em municípios pequenos e médios. O governo federal estimulou e promoveu esse tipo de iniciativa, e esse teria sido o caso na experiência relativa ao CIF, pois, desde 2005, o Sebrae Nacional executava o projeto de desenvolvimento do sudoeste do 
Paraná e oeste de Santa Catarina na região da faixa de fronteira com o extremo oriente da Argentina, o Profronteira.

Sobre o território do CIF, cabe sublinhar primeiramente que o continuum urbano não implica todos os municípios, embora caracterize a maioria, a saber, Barracão, Dionísio Cerqueira e Bernardo de Irigoyen. A área urbana de Bom Jesus do Sul dista cerca de nove quilômetros da área de Barracão, a mais próxima do núcleo. A população do conjunto atingiu quase 35 mil habitantes em 2010, tendo crescido menos de $4 \%$ desde o início daquela década (ver Tabela 1). Dionísio Cerqueira respondia por $42 \%$ do total, repetindo a participação de 2000, e Barracão figurava como o segundo em representatividade populacional, concentrando cerca de $28 \%$ nas duas datas. A Tabela 1 permite saber que os três municípios brasileiros exibem índices de desenvolvimento humano (IDH-M) bem inferiores aos da totalidade de seus estados: no Paraná, o IDH-M atingiu 0,650 e 0,749, em 2000 e 2010, respectivamente; em Santa Catarina, o índice alcançou 0,674 e 0,774, nos mesmos anos (ATLAS..., 2013). Não se conseguiu encontrar esse indicador para Bernardo de Irigoyen, mas a Provincia de Misiones registra, desde meados dos anos 1990, um IDH total muito inferior ao da Argentina como um todo: o dado mais recente, para 2010, é de 0,817 para Misiones contra 0,848 para o país (CATTERBERG; MERCADO, 2013).

Tabela 1 - CIF: alguns dados dos municípios participantes (início da década de 2000)

\begin{tabular}{|c|c|c|c|c|}
\hline \multirow[t]{2}{*}{ Município } & \multicolumn{2}{|c|}{ População total } & \multicolumn{2}{|c|}{$\begin{array}{c}\text { Índice de } \\
\text { desenvolvimento } \\
\text { humano (IDH-M) }\end{array}$} \\
\hline & 2000 & 2010 & 2000 & 2010 \\
\hline Dionísio Cerqueira (SC/BR) & 14.250 & 14.811 & 0,590 & 0,706 \\
\hline Barracão (PR/BR) & 9.603 & 9.735 & 0,613 & 0,706 \\
\hline Bom Jesus do Sul (PR/BR) & 4.154 & 3.796 & 0,544 & 0,697 \\
\hline $\begin{array}{l}\text { Bernardo de Irigoyen (Misiones/ } \\
\text { ARG) }\end{array}$ & $5.576^{(*)}$ & 6.492 & nd & nd \\
\hline Total & 33.583 & 34.834 & nd & nd \\
\hline
\end{tabular}

Fonte: Dionísio Cerqueira, Barracão e Bom Jesus do Sul: Atlas (2013); Bernardo de Irigoyen: República Argentina ([S.d.]a,b)

Nota: (*) Dado para 2001.

Pelo menos no lado brasileiro, a área do consórcio, incluindo os espaços adjacentes, é fortemente caracterizada por atividades agrícolas e agroindustriais.

É assim na região polarizada por Francisco Beltrão, a maior cidade do sudoeste paranaense nas proximidades. Na estrutura produtiva desse território, há 
muitos pequenos e médios produtores agropecuários que, com recursos principalmente familiares, interagem com indústrias alimentares. Isso se traduz em numerosos pequenos frigoríficos, em cooperativas ligadas ao setor lácteo e em atividades de esmagamento de oleaginosas e produção de ração (REDES..., 2000). A região apresenta baixas taxas de crescimento e registra evasão populacional, algo evidente, na área do CIF, no município de Bom Jesus do Sul, cuja população caiu mais ou menos 9\% entre 2000 e 2010, conforme a Tabela 1.

No lado catarinense, a cidade mais próxima de maior importância é São Miguel do Oeste, que exerce polarização de intensidade moderada em entorno de perfil econômico amplamente agroindustrial. Os traços essenciais, com presença histórica em praticamente todo o oeste de Santa Catarina, dizem respeito à produção de suínos e aves, em sistema de integração com grandes empresas que se dedicam ao abate e processamento de carnes e comercializam, inclusive, no exterior. A estrutura fundiária da região, vale realçar, ostenta uma miríade de pequenas e médias propriedades.

Uma particularidade do extremo oeste catarinense é o significado econômico do movimento de importações e exportações em Dionísio Cerqueira, haja vista a presença de um porto seco na fronteira com Bernardo de Irigoyen. Esse porto possui, de um lado, aduanas específicas para pedestres e veículos de passeio e, de outro lado, aduanas para caminhões de carga, desempenhando, assim, um papel que repercute não só no município, mas na região como um todo (REDE..., 2009). A movimentação comercial cresceu com a oficialização do trânsito de mercadorias e pessoas em 1979, e a instalação, em 2003, do ponto de fronteira alfandegado intensificou ainda mais essa dinâmica.

De fato, o volume movimentado passou de US\$ 85,5 milhões para cerca de US $\$ 443$ milhões, entre 2000 e 2012, quanto às vendas brasileiras, e de US\$ 69 milhões para US $\$ 374,5$ milhões no tocante às importações, ambas as trajetórias com oscilações, porém com tendência ascendente. O mesmo não ocorreu na comparação com os totais para Santa Catarina. As exportações pelo porto seco oscilaram entre $3,1 \%$ e $4,7 \%$ do total catarinense, entre 2000 e 2005, giraram em torno de $1 \%$ desde então até 2009 e, depois, subiram em saltos até atingir quase 5\% em 2012. As importações exibiram participação bastante errática até 2002, mas a partir desse ano o percurso foi de queda contínua e suave, praticamente linear, até o final do período (ver Figura 2). 
Figura 2 - Movimentação comercial no porto seco de Dionísio Cerqueira (20002012)

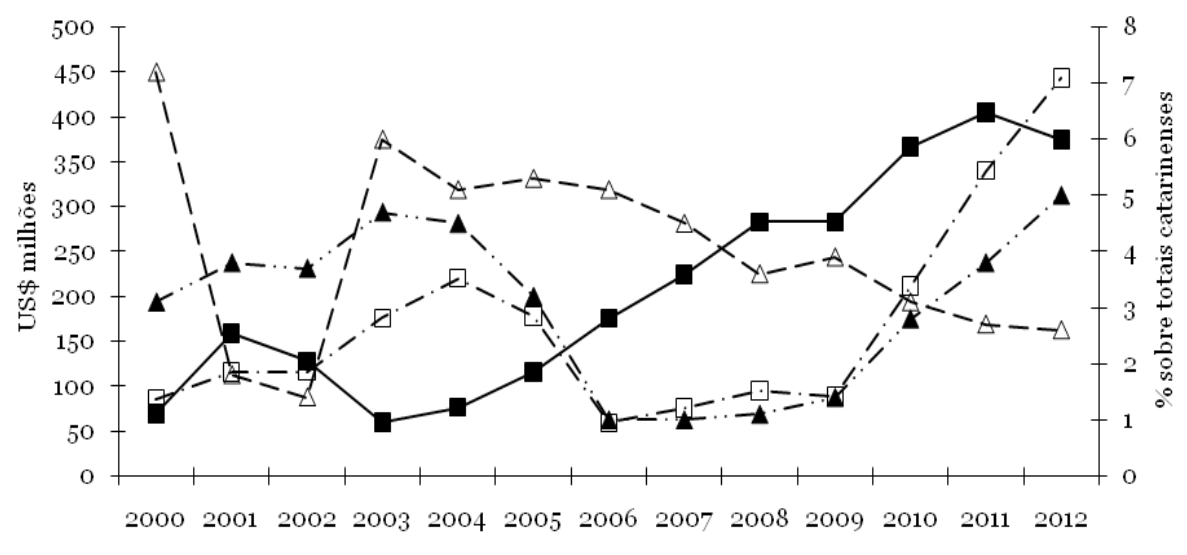

\begin{tabular}{|ll|}
\hline$-\square-$ Exportações brasileiras & $\longrightarrow$ - Importações brasileiras \\
$-\star-\%$ sobre exportações catarinenses & $-\leftarrow-\%$ sobre importações catarinenses \\
\hline
\end{tabular}

Fonte: Elaboração própria a partir de dados de Aliceweb.

Sobre o lado argentino, deve-se assinalar que a província de Misiones tem no setor terciário, especialmente no comércio, as atividades de maior peso no produto econômico. Depois aparecem os setores da construção e da indústria de transformação, nesta segunda com maior representatividade dos segmentos para os quais a madeira é origem dos principais insumos, como pasta de madeira e papel/papelão. Esses dois tipos de produtos, aliás, são os que mais se destacam nas exportações de Misiones, seguidos de erva-mate, tabaco e frutas cítricas (CÁMARA ARGENTINA DE COMERCIO, 2011).

Assinalou-se, no início do artigo, que processos de integração tendem a estimular iniciativas locais de cooperação, envolvendo agentes em diferentes lados das fronteiras, voltadas ao enfrentamento de problemas e à promoção do desenvolvimento coletivamente. Essa configuração não está ausente do CIF abordado neste artigo. Seu elenco de ações, divulgado em meados de 2011 (CONSÓRCIO INTERMUNICIPAL DA FRONTEIRA, 2011), é eloquente sobre o previsto escopo da iniciativa. O Quadro 1 apresenta algumas ações principais por área de intervenção e com os resultados esperados.

Uma ação estratégica de planejamento e promoção do desenvolvimento regional, centro de gravidade de muito do que foi contemplado, refere-se ao Programa Líder, integrante das iniciativas do Sebrae em escala nacional (com presença em diversos estados) para formar lideranças em nível de território. Dois aspectos merecem maior realce sobre esse assunto. Um é que, instalado na área do CIF em julho de 2009, com a presença - além dos prefeitos e outras lideranças locais - dos 
governadores de Santa Catarina, Paraná e Misiones e de senadores e deputados federais e estaduais, esse programa ultrapassou a composição do consórcio: foram atingidos quase todos os municípios do Profronteira, executado pelo Sebrae Nacional desde 2005. Outro aspecto é a sua projeção transfronteiriça em país vizinho, algo que chama a atenção, embora o Profronteira também incluísse municípios da província de Misiones.

Quadro 1 - CIF: principais ações previstas e resultados esperados

\begin{tabular}{|c|c|}
\hline Áreas de atuação e ações previstas & Resultados esperados \\
\hline \multicolumn{2}{|c|}{ Planejamento do desenvolvimento regional } \\
\hline $\begin{array}{l}\text { Lançar o Programa Líder (Sebrae) e o } \\
\text { Projeto Parque Turístico Ambiental de } \\
\text { Integração. }\end{array}$ & $\begin{array}{l}\text { Proposta de desenvolvimento centrada } \\
\text { em educação, turismo, agroecologia e } \\
\text { produtos locais, os eixos privilegiados, com } \\
\text { execução. }\end{array}$ \\
\hline \multicolumn{2}{|r|}{ Saúde } \\
\hline $\begin{array}{l}\text { Fazer o projeto de reforma e aumento } \\
\text { do Hospital Municipal de Dionísio } \\
\text { Cerqueira. }\end{array}$ & $\begin{array}{l}\text { Melhores condições de atendimento } \\
\text { hospitalar, oferecendo-o de modo } \\
\text { integrado na área transfronteiriça do CIF. }\end{array}$ \\
\hline $\begin{array}{l}\text { Implantar transporte integrado de } \\
\text { pacientes. }\end{array}$ & $\begin{array}{l}\text { Transporte mais eficiente e com menores } \\
\text { custos. }\end{array}$ \\
\hline \multicolumn{2}{|c|}{ Previdência Social } \\
\hline $\begin{array}{l}\text { Instalar agência do INSS na tríplice } \\
\text { fronteira. }\end{array}$ & $\begin{array}{l}\text { Melhor desempenho na fiscalização e no } \\
\text { encaminhamento dos benefícios. }\end{array}$ \\
\hline \multicolumn{2}{|r|}{ Turismo } \\
\hline $\begin{array}{l}\text { Criar o parque turístico ambiental de } \\
\text { integração. }\end{array}$ & $\begin{array}{l}\text { Revitalização do rio Peperi-Guaçu e } \\
\text { aparato de promoção de turismo, lazer e } \\
\text { intercâmbio sociocultural. }\end{array}$ \\
\hline $\begin{array}{l}\text { Construir o Centro de Atendimento ao } \\
\text { Turista. }\end{array}$ & $\begin{array}{l}\text { Maior satisfação para os turistas } \\
\text { edesmMercosul vale para osr, sua } \\
\text { permanência mais longa na área. }\end{array}$ \\
\hline $\begin{array}{l}\text { Construir nova aduana integrada de } \\
\text { turismo. }\end{array}$ & $\begin{array}{l}\text { Melhor e mais rápido atendimento aos } \\
\text { turistas. }\end{array}$ \\
\hline \multicolumn{2}{|c|}{ Habitação e Urbanismo } \\
\hline $\begin{array}{l}\text { Zerar o déficit habitacional e implantar } \\
\text { sistema de saneamento básico. }\end{array}$ & $\begin{array}{l}\text { Oferta de centenas de casas populares e } \\
\text { redes de esgoto sanitário e distribuição de } \\
\text { água. }\end{array}$ \\
\hline $\begin{array}{l}\text { Elaborar projeto integrado de reciclagem } \\
\text { do lixo. }\end{array}$ & $\begin{array}{l}\text { Organização dos catadores de lixo e coleta } \\
\text { seletiva com menores custos. }\end{array}$ \\
\hline Realizar projeto urbanístico integrado. & $\begin{array}{l}\text { Vias melhor sinalizadas, com padronização } \\
\text { transfronteiriça das placas e informações. }\end{array}$ \\
\hline
\end{tabular}




\begin{tabular}{|c|c|}
\hline Áreas de atuação e ações previstas & Resultados esperados \\
\hline \multicolumn{2}{|c|}{ Educação } \\
\hline Criar escola bilíngue de fronteira. & $\begin{array}{l}\text { Formação de cidadãos bilíngues e } \\
\text { interativos social e culturalmente. }\end{array}$ \\
\hline $\begin{array}{l}\text { Capacitar e formar professores de forma } \\
\text { integrada. }\end{array}$ & $\begin{array}{l}\text { Formação de melhor qualidade e } \\
\text { capacitação integrada, com trocas de } \\
\text { experiências. }\end{array}$ \\
\hline \multicolumn{2}{|c|}{ Agricultura } \\
\hline Fortalecer a produção da fruticultura. & $\begin{array}{l}\text { Associação e cantina dos vitivinicultores } \\
\text { mais fortes e melhor equipadas. }\end{array}$ \\
\hline Fortalecer a cadeia produtiva do leite. & $\begin{array}{l}\text { Fábrica do Produtor, em Bom Jesus do } \\
\text { Sul, mais forte, e renda dos produtores } \\
\text { familiares mais elevada. }\end{array}$ \\
\hline Criar patrulha agrícola conjunta. & $\begin{array}{l}\text { Melhores qualidade e eficiência dos } \\
\text { serviços, com menores custos. }\end{array}$ \\
\hline \multicolumn{2}{|c|}{ Infraestrutura para o desenvolvimento econômico } \\
\hline $\begin{array}{l}\text { Definir traçado da ferrovia da integração } \\
\text { entre Itajaí e Dionísio Cerqueira. }\end{array}$ & $\begin{array}{l}\text { Definição apta a sustentar posteriores } \\
\text { medidas de implantação. }\end{array}$ \\
\hline $\begin{array}{l}\text { Construção da Ruta } 14 \text { entre Bernardo } \\
\text { de Irigoyen e San Pedro, em Misiones. }\end{array}$ & Melhor transporte rodoviário de cargas. \\
\hline $\begin{array}{l}\text { Construção de nova aduana integrada } \\
\text { de cargas. }\end{array}$ & Melhores serviços de aduana. \\
\hline \multicolumn{2}{|c|}{ Segurança pública } \\
\hline $\begin{array}{l}\text { Implantar o Programa Nacional de } \\
\text { Segurança e Cidadania. }\end{array}$ & $\begin{array}{l}\text { Melhor monitoramento da fronteira e } \\
\text { maior controle da criminalidade. }\end{array}$ \\
\hline
\end{tabular}

Fonte: Elaboração própria a partir de Consórcio Intermunicipal da Fronteira (2011).

Vale notar que o desdobramento, sobre um território muito maior, de uma iniciativa ligada a um consórcio delimitado espacialmente acena com promissoras interações entre a implicada área urbana transfronteiriça e o seu entorno ou hinterland. Isso possivelmente dificultaria, ao menos em princípio, a configuração de um problemático - e, logicamente, indesejável - quadro de enclave, nos termos abordados anteriormente.

Entre as providências enfeixadas na tentativa de promover o desenvolvimento regional, destaca-se o projeto identificado como Caminhos da Fronteira. Sua abrangência eram os municípios fronteiriços e seu eixo - ao menos nas intenções declaradas - era o desenvolvimento sustentável. Almejando criar condições para uma melhor qualidade de vida local, as propostas privilegiaram, atribuindo-lhes o caráter de importância estratégica, as ações em educação, turismo e agroecologia, esta representando estímulo à produção de itens nos próprios ambientes envolvidos, incluindo o artesanato. De acordo com a segunda edição do Caderno das Ações Integradas, divulgado no início de 2013, as atividades executadas englo- 
baram vários encontros de capacitação para formação de líderes e a realização da Feira das Potencialidades Caminhos da Fronteira, durante a nona Festa da Integração, em 2010 (CONSÓRCIO..., 2013a).

Especificamente sobre o turismo, deve-se assinalar, sobretudo, que, junto com o mencionado Programa Líder, ocorreu o lançamento do Projeto Parque Turístico Ambiental de Integração (Ptai). O início das respectivas obras foi anunciado em março de 2011, mas, pelas informações contidas na segunda edição do Caderno das Ações Integradas (CONSÓRCIO..., 2013a), o começo deuse em 2012, com recursos de várias fontes públicas no Brasil e na Argentina. O empreendimento contemplava diferentes equipamentos e, inclusive, um lago oriundo da revitalização da nascente do rio Peperi-Guaçu. A expectativa era que as programadas condições para atividades recreativas, culturais, gastronômicas, comerciais e desportivas, estruturadas em torno desse lago, e os previstos elementos de mobiliário urbano impregnados de sentido até mesmo simbólico, evocativo da vida regional, pudessem promover os aspectos sociais daquele espaço, estimulando intercâmbios e, assim, o turismo na área, com seus efeitos econômicos e socioculturais.

Quanto à agricultura e à agroindústria, criou-se uma patrulha agrícola com recursos dos municípios para compra de caminhões, patrola e retroescavadeira. A operacionalização envolvia a disponibilidade, pelas prefeituras, de funcionários cujos serviços seriam itinerantes, permanecendo temporariamente em cada lugar (DEBONA, 2011). As ações de fortalecimento da fruticultura e da cadeia do leite continuavam em execução em 2013. A segunda implicava a melhoria das condições de funcionamento da Fábrica do Produtor de Bom Jesus do Sul (Farbom), integrante de um programa do governo paranaense denominado Fábrica do Produtor do Paraná. Quanto à fruticultura, continuavam em execução ações de fortalecimento das quais fazia parte a promoção da associação e da cantina de vitivinicultores (CONSÓRCIO..., 2013a).

Outras medidas também haveriam de repercutir, sobretudo as referentes à infraestrutura. Merecem destaque os serviços aduaneiros, tanto que uma nova aduana integrada de cargas Brasil-Argentina encontrava-se em construção. Deve-se dizer o mesmo para as iniciativas voltadas aos transportes, envolvendo a Ruta 14, numa extensão de 56 km entre Bernardo de Irigoyen e San Pedro, em Misiones, e a programada Ferrovia da Integração, entre Itajaí e Dionísio Cerqueira, em Santa Catarina. Esta, também conhecida como Ferrovia do Frango, por interligar as áreas de produção de carnes de aves no oeste e meio-oeste do estado e o porto de Itajaí, foi confirmada pelo Departamento Nacional de Infraestrutura de Transportes (Dnit). Suas obras seriam iniciadas em 2015, a julgar pelas previsões quando da assinatura em Chapecó (em maio de 2013), pelo Ministro dos Transportes, do edital de lançamento do estudo de viabilidade técnica e ambiental (DEBONA, 2013). 
No setor mais propriamente social, na área de educação, merece destaque que a iniciativa, objetivando a autorização do Instituto Federal do Paraná (IFPR), frutificou em unidade instalada em Barracão, registrando-se o início das atividades de formação em nível médio. Esforços foram realizados também com vistas a uma extensão local da Universidade Federal da Integração Latino-Americana (Unila), sediada em Foz do Iguaçu, assim como à escola bilíngue de fronteira.

$\mathrm{Na}$ área da saúde, as atividades de reforma e ampliação do Hospital Municipal de Dionísio Cerqueira, visando adequá-lo ao atendimento de pessoas do território do CIF, foram iniciadas em junho de 2012 com recursos do Ministério da Saúde. Posteriormente, o hospital recebeu um tomógrafo computadorizado da Receita Federal (que havia sido apreendido em 2013) em doação representativa de importante incorporação aos seus equipamentos.

No que concerne à previdência social, avançava a construção da agência do INSS de Dionísio Cerqueira, cujo atendimento deveria recobrir nove municípios da região, entre eles, logicamente, os integrantes do CIF. O melhor acesso dos habitantes aos serviços, envolvendo o encaminhamento e a fiscalização dos benefícios, haverá de ser o resultado de uma importante articulação de esforços promovida institucionalmente pelo consórcio.

Não é ocioso colocar que várias iniciativas protagonizadas no âmbito do CIF foram motivadas por problemas que costumam caracterizar numerosas cidades brasileiras, principalmente, talvez, em municípios de menor porte. Com efeito, mostram-se recorrentes no cenário urbano brasileiro as carências em saúde, educação, segurança e habitação, para mencionar algumas áreas contempladas pelas ações previstas no consórcio. Apesar disso, a anunciada intenção de que o hospital localizado em Dionísio Cerqueira atenda também cidadãos argentinos, após sua reforma e ampliação, e as propostas para a ampliação da escola bilíngue e capacitação integrada de professores, refletem claramente a condição fronteiriça.

Em outras iniciativas percebe-se, mais do que a influência de uma fronteira, em termos gerais, a representatividade daquela condição fronteiriça específica. Têm destaque nesse grupo as ações ligadas ao turismo. Nos meses de verão, o litoral de Santa Catarina é frequentemente visitado por muitos argentinos que, em diversos casos, adentram o território brasileiro pela fronteira em questão. Assim, as previstas providências em infraestrutura e serviços, com vistas a uma efetiva inserção local na, por assim dizer, economia do turismo - abrangendo o estímulo aos passantes para que pernoitem e consumam -, guardam relação direta com aquela particularidade. $\mathrm{O}$ mesmo pode ser dito com respeito aos projetos da rubrica "infraestrutura para o desenvolvimento", entre os quais se deve sublinhar a construção de uma nova aduana de cargas.

Na sua totalidade, as ações protagonizadas com repercussões tanto econômicas quanto socioculturais poderão impulsionar os municípios mais diretamente 
implicados e, ainda, toda a região. Faz sentido que novas oportunidades e possibilidades sejam esperadas, com aproveitamento pelas populações locais e mesmo por outros contingentes, atraídos desde diferentes origens, sobretudo do entorno regional.

\section{Considerações Finais}

O processo de integração no Cone Sul, sinuoso e marcado por assimetrias e desigualdades - simultaneamente legadas pela história e reflexos da própria integração -, oportuniza a cooperação transfronteiriça nas esferas privada e pública. A cooperação institucional foi o principal foco de atenção neste artigo, que explorou um ângulo específico dessa prática: cooperação entre estruturas de governo e/ou instituições atuando em escala territorial, envolvendo particularmente municípios ou cidades.

A experiência efetivamente explorada foi a do CIF, entrelaçando quatro municípios fronteiriços - três no Brasil e um na Argentina - com o propósito de equacionar problemas e promover o desenvolvimento coletivamente. Sobressai, em termos de participação, o município de Dionísio Cerqueira, que ostenta um porto seco na fronteira com Bernardo de Irigoyen, um envolvimento que, especialmente por causa dessa infraestrutura, reflete de alguma forma a dinâmica comercial do Mercosul.

Pode-se considerar que o contexto mais geral dessa experiência refere-se à dinâmica, impulsionada pela globalização, de ampliação e fortalecimento das iniciativas internacionais protagonizadas por entes subnacionais. Vinculado à transferência pelo Estado central de atribuições administrativas e técnicas, incluindo as de promoção do desenvolvimento, para escalas territoriais menos abrangentes de ação pública, esse movimento contribuiu para que a cooperação internacional entre estruturas políticas e administrativas subnacionais - entre elas, com destaque, as municipais (cidades, de um modo geral) - ganhasse corpo e visibilidade, conforme reconhecido e estimulado no âmbito de instituições como o Banco Mundial.

$\mathrm{O}$ Brasil não ficou à margem desse processo. Apesar da pouca agilidade no avanço das práticas associadas e das lacunas institucionais (não obstante a ênfase atribuída pela Constituição Federal de 1988 à descentralização administrativa), a paradiplomacia exibiu crescimento no país. Isso se traduziu em uma multiplicação de acordos, convênios e outras formas de interações institucionais transfronteiriças entre entes subnacionais que foram favorecidas e estimuladas - no que concerne ao Cone Sul como palco das iniciativas - pela própria dinâmica de integração regional. Assuntos ou problemas relacionados, por exemplo, com infraestruturas e diversos tipos de serviços figuram no centro dessas ações, provocando e merecen- 
do cooperação técnica, trocas de experiências e parcerias, em geral, sob o signo do pragmatismo, na busca de equacionamento para dificuldades concretas.

O CIF, focalizado neste artigo, representa a referida prática. Também nesse consórcio vigora um sentido prático, como sugere o rol de medidas contempladas, e a iniciativa de criação da correspondente estrutura transfronteiriça reflete o entendimento das lideranças municipais de que seus espaços de atuação administrativa e política compartilham problemas cujo equacionamento demanda procedimentos conjuntos e cooperativos. As previstas áreas de atuação coincidem, em boa medida, com o que costuma caracterizar a cooperação internacional implicando entes subnacionais, de uma forma geral. Porém, o caráter de fronteira internacional entre Dionísio Cerqueira e Bernardo de Irigoyen, em que se verifica considerável movimento de cargas e também de argentinos que se dirigem às praias do sul do Brasil durante o verão, confere alguma particularidade às ações concebidas. No conjunto, as iniciativas previstas enfeixam-se em torno da problemática geral da promoção do desenvolvimento socioeconômico em sintonia com o reconhecimento de que, apesar dos recortes estabelecidos pelas fronteiras (entre países e entre entes subnacionais), agir conjunta e cooperativamente pode representar um caminho para melhores condições de trabalho e vida em território situado no epicentro do Mercosul.

Portanto, esse consórcio mereceria ser acompanhado pelos interessados, seja na integração regional, seja no desenvolvimento em escala territorial, tanto quanto pelos que estudam as interações internacionais entre entes subnacionais. O mesmo pode ser dito, com respeito a Santa Catarina, Paraná e Misiones, sobre quem se interessa pela socioeconomia desses estados e da província, de uma maneira ampla, pois as ações do CIF em questão parecem aptas a produzir efeitos até em áreas não propriamente adjacentes ao seu centro de gravidade, podendo atingir dimensões amplamente extra locais.

\section{Referências}

ALGER, C. F. The future of democracy and global governance depends on widespread public knowledge about local links to the world. Cities, v. 16, n. 3, p. 195-206, 1999.

ARGENTINA. Instituto Nacional de Estadística y Censos. Censo 2001. Buenos Aires: INDEC, [S.d.]a. Disponível em: <https://www.indec.gov.ar/nivel4_default.asp?id_tema_1=2Eid_ tema_2=41Eid_tema_3=134>.Acesso em: 10 jun. 2018.

Instituto Nacional de Estadística y Censos. Censo 2010. Buenos Aires: INDEC,

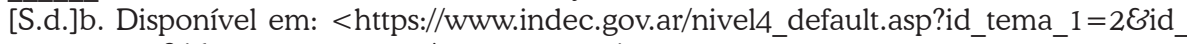
tema_2=41Eid_tema_3=135>.Acesso em: 10 jun. 2018.

ATLAS do Desenvolvimento Humano no Brasil. Brasília, DF: PNUD; Fundação João Pinheiro; Ipea, 2013. Disponível em: < http://www.atlasbrasil.org.br/2013>. Acesso em: 17 fev. 2015. 
BLYDE, J. S.; FERNÁNDEZ-ÁRIAS, E.; GIORDANO, P. (Ed.). Deepening integration in Mercosur: dealing with disparities. Washington: Inter-American Development Bank, 2008.

BOISIER, S. Desarrollo territorial y descentralización: el desarrollo en el lugar y en las manos de la gente. Revista EURE, v. 30, n. 90, p. 27-40, 2004.

BRASIL. Presidência da República. Constituição da República Federativa do Brasil. Brasil, 1988. Disponível em: <http://www.planalto.gov.br/ccivil_03/constituicao/constituicaocompilado. htm>. Acesso em: 17 jun. 2017.

BYÉ, M. Localisation de l'investissement et Communauté Economique Européenne. Revue Economique, v. 9, n. 2, p. 188-212, 1958.

CÁMARA ARGENTINA DE COMERCIO. Informe económico: provincia de Misiones. Buenos Aires: Cámara Argentina de Comercio, 2011.

CATTERBERG, G.; MERCADO, R. (Dirs.). Informe nacional sobre desarrollo humano 2013: Argentina en un mundo incierto: asegurar el desarrollo humano en el siglo XXI. Buenos Aires: Pnud, 2013.

CONSÓRCIO INTERMUNICIPAL DA FRONTEIRA. Caderno das ações integradas. Barracão, PR: CIF, 2011. Disponível em: <http://www.cifronteira.com.br>. Acesso em: 8 dez. 2011.

. 2. ed. Barracão, PR: CIF, 2013a. Disponível em: <http://cif.inovecode.com.

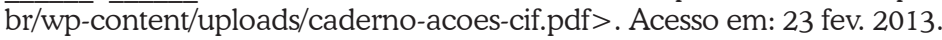

. Protocolo de intenções. Barracão, PR: CIF, 2013b. Disponível em: < http://cifronteira. com.br/wp-content/uploads/2014/05/PROTOCOLO-DE-INTEN\%C3\%87\%C3\%95ES.pdf> . Acesso em: 23 fev. 2015.

DANIEL, M. C. M. O Itamaraty e os governos subnacionais. In: SEMINÁRIO INTERNACIONAL ENTRE O LOCAL E O GLOBAL: governos subnacionais e sociedade civil na integração regional, 2002, São Paulo. Cadernos Cedetec, São Paulo, n. 71, p. 45-48, 2002.

DEBONA, D. Ferrovia do frango: obras vão começar em dois anos. Diário Catarinense, Florianópolis, 11 maio 2013. p. 12.

. Integração regional: quatro cidades e um objetivo. Diário Catarinense, Florianópolis, 7 ago. 2011. p. 33.

ECONOMÍA y territorio en América Latina y el Caribe: desigualdades y políticas. Santiago de Chile: Cepal, 2009.

FARAH, M. F. S. Gestão pública local, novos arranjos institucionais e articulação urbanoregional. In: GONÇALVES, M. F.; BRANDÃO, C. A.; GALVÃO, A. C. (Orgs.). Regiões e cidades, cidades nas regiões: o desafio urbano-regional. São Paulo: Unesp; Anpur, 2003. p. 81-94.

GAUDEMAR, J.-P. Débat: l'aménagement do territoire: nouvelles donnes? L'Espace Géographique, v. 4, p. 273-290, 1989. 
GENEYRO, R. et al. La integración productiva regional y los gobiernos locales del Mercosur: estudio situacional. Montevideo: Secretaría Técnica Permanente de Mercociudades, 2010. Disponível em: <www.inmercociudades.org/web2010/docs/publicaciones/diagnostico_ integracion_productiva_I.pdf $>$. Acesso em: 15 dez. 2011.

JACOBSON, D. New frontiers: territory, social spaces, and the state. Sociological Forum, v. 12, n. 1, p. 121-133, 1997.

JAGUARIBE, H. Intervenção no debate sobre o tema "América do Sul no atual sistema internacional". In: SEMINẢRIO SOBRE A AMÉRICA DO SUL: a organização do espaço sulamericano: seu significado político e econômico, 2000, Brasília, DF. Anais... Brasília: IRBr; Ipea; BID, 2000. p. 41. v. 2.

KRUGMAN, P. Geography and trade. Cambridge: The MIT Press; Leuven: Leuven University, 1991.

LAURELLI, E.; MONTAÑA, E. Los territorios del Mercado Comum del Sur: propuestas y efectos esperados. Revista Interamericana de Planificación, Quito, Ecuador, v. 27, n. 106, p. 138-149, abr./jun. 1994.

LINS, H. N. Mercosul: destaque para a cooperação. Textos de Economia, Florianópolis, v. 5, n. 1, p. 55-76, 1994.

LINS, H. N.; BERCOVICH, N. A. Cooperação envolvendo pequenas e médias empresas industriais no Mercosul. Ensaios FEE, Porto Alegre, v. 16, n. 1, p. 277-295, 1995.

MADOERY, O. Política y territorio en Argentina. Desenvolvimento Regional em Debate, Canoinhas, SC, v. 1, n. 1, p. 24-39, 2011.

MANN, M. Has globalization ended the rise and rise of the nation-state? Review of International Political Economy, v. 4, n. 3, p. 472-496, 1997.

MARCOVITCH, J.; DALLARI, P. B. A. (Orgs.). Relações internacionais de âmbito subnacional: a experiência de estados e municípios no Brasil. São Paulo: Instituto de Relações Internacionais, Universidade de São Paulo, 2014.

MERCOSUL/CMC/DEC. No 03/07. Instituto Social do MERCOSUL. Rio de Janeiro: CMC, 18 jan. 2007. Disponível em: <http://www.sice.oas.org/Trade/MRCSRS/Decisions/dec0307p. pdf $>$ Acesso em: 10 jun. 2018

MERCOSUL/CMC/DEC. No 18/05. Integração e funcionamento do Fundo para a Convergência Estrutural e Fortalecimento da Estrutura Institucional do MERCOSUL. Assunção: CMC, 19 jun. 2005. Disponível em: <http://www.sice.oas.org/Trade/MRCSRS/Decisions/dec1805p.asp> Acesso em: 10 jun. 2018.

MILANI, C. R. S.; RIBEIRO, M. C. M. International relations and the paradiplomacy of Brazilian cities: crafting the concept of local international management. Brazilian Administration Review, v. 8, n. 1, p. 21-36, 2011.

MORAIS, M. P.; COSTA, M. A. (Org.). Infraestrutura social e urbana no Brasil: subsídios para uma agenda de pesquisa e formulação de políticas públicas. Brasília: Ipea, 2010. v. 2. (Série Eixos Estratégicos do Desenvolvimento Brasileiro, Livro 6). 
MOULAERT, F.; SWYNGEDOUW, E.; WILSON, P. Spatial responses to Fordist and postFordist accumulation and regulation. Papers of the Regional Science Association, v. 64, p. 11-23, 1988.

ORGANISATION FOR ECONOMIC CO-OPERATION AND DEVELOPMENT. Building competitive regions: strategies and governance. Paris: OECD, 2005.

PEREIRA, J. A. L. O federalismo na diplomacia brasileira: o interesse do Itamaraty nas ações externas de governos subnacionais. Revista Cena Internacional, Brasília, v. 6, n. 2, p. 144-159, 2005 .

RAPOPORT, M. Os Estados nacionais frente à globalização. Revista Brasileira de Política Internacional, Brasília, v. 40, n. 2, p. 166-171, 1997.

REDE de avaliação e de capacitação para implementação dos planos diretores participativos: Dionísio Cerqueira. Brasília: Ministério das Cidades; Blumenau: Furb/Neur, 2009. Disponível em: < http://www.observatoriodasmetropoles.net/planosdiretores/poduts/sc/SC_Avaliação_ PDP_Dionísio_Cerqueira_fev_2010.pdf>. Acesso em: 7 dez. 2011.

REDES Urbanas Regionais: Sul. Brasília: Ipea; IBGE; Unicamp/IE/Nesur; Ipardes, 2000. (Série Caracterização e Tendências da Rede Urbana do Brasil, v. 6).

ROBINSON, W. I. Beyond nation-state paradigms: globalization, sociology, and the challenge of transnational studies. Sociological Forum, v. 13, n. 4, p. 561-594, 1998.

SALOMÓN, M. Local governments as foreign policy actors and global cities network makers: the cases of Barcelona and Porto Alegre. Globalization and World Cities Research Bulletin, n. 305, p. 1-14, 2009. Disponível em: <http://www.lboro.ac.uk/gawc/rb/rb305.html >. Acesso em: 4 abr. 2013.

. Los estados y municipios brasileños como actores de la cooperación internacional. Revista Española de Desarrollo y Cooperación, Madrid, v. 22, p. 145-159, 2008.

SARAIVA, J. F. S. A busca de um novo paradigma: política exterior, comércio externo e federalismo no Brasil. Revista Brasileira de Política Internacional, Brasília, v. 47, n. 2, p. 131162, 2004.

SASSEN, S. Sociologia da globalização. Porto Alegre: Artmed, 2010.

SAUSI, J. L. R.; ODDONE, N. La cooperación transfronteriza entre las unidades subnacionales del Mercosur. Tendencias, Pasto, Nariño, Colombia, v. 11, n. 2, p. 131-159, 2010.

SEMINÁRIO INTERNACIONAL ENTRE O LOCAL E O GLOBAL: governos subnacionais e sociedade civil na integração regional, 2002, São Paulo. Cadernos Cedetec, São Paulo, n. 71, 2002 .

SEMINÁRIO POLÍTICAS DE INTEGRACIÓN REGIONAL: experiencias locales exitosas en el Mercosur, 2007, Tandil, Argentina. Actas... [S. 1]: [s. n.], 2007. Disponível em: <www.dhl. hegoa.ehu.es/ficheros/0000/0468/libro_Experiencias_locales_exitosas_en_Mercosur_2007. pdf > . Acesso em: 2 dez. 2011. 
SOUZA, A. M.; OLIVEIRA, I. T. M.; GONÇALVES, S. S. Integrando desiguais: assimetrias estruturais e políticas de integração no Mercosul. Rio de Janeiro: Ipea, 2010. (Texto para Discussão, n. 1477).

SOUZA, C. Federalismo e descentralização na Constituição de 1988: processo decisório, conflitos e alianças. DADOS - Revista de Ciências Sociais, Rio de Janeiro, v. 44, n. 3, p. 513560, 2001.

THE WORLD BANK. Cities in transition: World Bank urban and local government strategy. Washington, D. C.: The World Bank, 2000. Disponível em: <http://www.ucl.ac.uk/dpuprojects/drivers_urb_change/urb_governance/pdf_capa_building/WorldBank_urban_and_ local_gov_strategy.pdf $>$. Acesso em: 11 abr. 2013.

UNITED NATIONS ADVISORY COMMITTEE OF LOCAL AUTHORITIES. Resolution 17/18: cooperation with partners: role of local authorities in the work of the commission. [S. 1.], 14 May 1999. Disponível em: <http://www.unhabitat.org/content.asp?cid=778E catid=491 $\mathcal{G}$ ty peid $=23$ EAllContent $=1>$. Acesso em: 2 mar. 2013.

VÁZQUEZ BARQUERO, A. Desenvolvimento endógeno em tempos de globalização. Porto Alegre: Editora da UFRGS; FEE, 2002.

VENABLES, A. J. Winners and losers from regional integration agreements. The Economic Journal, v. 113, p. 747-761, 2003.

VIGEVANI, T. Problemas para a atividade internacional das unidades subnacionais: estados e municípios. Revista Brasileira de Ciências Sociais, São Paulo, v. 21, n. 62, p. 127-169, 2006.

Recebido em: 01/03/2016.

Aceito em: 10/07/2017. 